Original Article

\title{
Changes in Neck Muscle Thickness Due to Differences in Intermittent Cervical Traction Force Measured by Ultrasonography
}

\author{
Katsushi KuniYasu, MS ${ }^{1)}$ \\ 1) Kawasaki University of Medical Welfare: 288 Matsushima, Kurashiki, Okayama 701-0193, Japan
}

\begin{abstract}
Purpose] Many patients receive intermittent cervical traction in a daily treatment setting. However, unified settings for traction force, duration, and direction have yet to be determined. Therefore, an objective index is required to determine changes in traction conditions or to indicate its effectiveness. [Subjects] Fifteen healthy males volunteers participated in this study. [Methods] The thickness of the trapezius and splenius capitis muscles before and during traction were measured using ultrasonography at three traction forces: 5,8 and $11 \mathrm{~kg}$. [Results] Significant differences in muscle thickness were observed at $11 \mathrm{~kg}$ in the trapezius, and at $8 \mathrm{~kg}$ and $11 \mathrm{~kg}$ in the splenius capitis muscles. The muscle thickness ratio of the trapezius muscle showed a significant difference between $11 \mathrm{~kg}$ and 5 and $8 \mathrm{~kg}$, and between $5 \mathrm{~kg}$ and 8 and $11 \mathrm{~kg}$, as well as between $8 \mathrm{~kg}$ and $11 \mathrm{~kg}$ for the splenius capitis muscles. [Conclusion] Differences in muscle direction between the trapezius and splenius capitis muscles may account for the contrasting results obtained at the $8 \mathrm{~kg}$ traction force. This finding suggests that cervical traction must be performed considering the effects on different neck regions.

Key words: Intermittent cervical traction, Muscle thickness, Ultrasonography
\end{abstract}

(This article was submitted Nov. 6, 2013, and was accepted Dec. 20, 2013)

\section{INTRODUCTION}

Therapeutic exercise and physiotherapeutics are important treatment methods in physical therapy, but recently, physiotherapeutics has become auxiliary to therapeutic exercise. However, physio -therapeutics is very often used to treat orthopedic patients and those with disability-related pain. Intermittent cervical traction is a physiotherapy approach that is used to treat patients with pain or stiffness in the neck and shoulder region. Many patients receive intermittent cervical traction in a daily treatment setting; however, the objective assessment of severity of symptoms such as pain and numbness is difficult. Therefore, evaluating the effectiveness of treatment must rely on self-reported symptoms. Furthermore, unified settings for traction force, duration, and direction in traction therapy have yet to be determined. Accordingly, a more objective index of evaluating treatment effectiveness which can determine changes in traction conditions or indicate its effectiveness is necessary. In this study, we evaluated changes to muscle thickness that occurred during intermittent cervical traction using ultrasonic diagnostic equipment that is frequently used to assess and diagnose patients with motor dysfunction.

Corresponding author. Katsushi Kuniyasu (E-mail: katsushi@mw.kawasaki-m.ac.jp)

(C2014 The Society of Physical Therapy Science. Published by IPEC Inc. This is an open-access article distributed under the terms of the Creative Commons Attribution Non-Commercial No Derivatives (by-ncnd) License $<$ http://creativecommons.org/licenses/by-nc-nd/3.0/>.

\section{SUBJECTS AND METHODS}

The subjects were 15 healthy males (height, $172.5 \pm$ $4.0 \mathrm{~cm}$; weight, $67.9 \pm 15.6 \mathrm{~kg}$; age, $21.3 \pm 1.8$ years) who were free of orthopedic disease of the neck and were not receiving treatment such as cervical traction. We applied intermittent cervical traction to the subjects and measured their muscle thicknesses before and during traction using an ultrasonic diagnostic device. The research aims and methods were explained to the subjects, and the experiment was performed after receiving their consent. The study protocol was approved by the research ethics committee of Kawasaki University of Medical Welfare (approval No. 421).

Traction was performed in a seated position in a reclining wheelchair with the subject's heads on the headrest positioned at a cervical flexion angle of $10^{\circ}$. We chose this position to prevent the muscles contracting to support the heads and to restrict movement of the head and neck to the minimum when capturing ultrasonic images. The traction forces were 5, 8 , and $11 \mathrm{~kg}$, and the traction cycle consisted of 20 seconds of traction and 10 seconds of rest. We randomized the order of the traction forces for each subject. Two cycles of each traction force were performed and ultrasonic images of muscle thickness were captured during the second cycle.

We used the ultrasonic image diagnostic device Prosound SSD-3500 (Aloka Co. Ltd.). Images were captured in B-mode (brightness mode) using a linear probe $(10 \mathrm{MHz})$ positioned on the outside of the fifth and seventh cervical vertebra, so that the trapezius and splenius capitis muscles were visible. We drew a line marker in the middle of the 
ultrasonic image for measurements of muscle thickness and took images of each subject using the same frequency and contrast conditions. We used the seventh cervical spinous process as a landmark so that the same area could be imaged before and after traction, and secured the probes to the fifth and sixth cervical spinous process using an adjustable frame and a custom-made probe holder.

We attached a $200 \mathrm{gf}$ constant load spring to the custom probe holder so that the probe and neck region would always be secured at the same force.

We measured the thickness of the trapezius and splenius capitis muscles from the images using the distance measuring functionality of the device. Muscle thicknesses before and during traction were measured, and we calculated the muscle thickness ratio during traction by normalizing the contraction value to the thickness before traction. Values are shown as muscle thickness ratios (\%). In order to confirm that the ultrasonic images were cuptured from the same region, we calculated the interclass correlation coefficients (ICC) of muscle thickness before traction for the three traction forces.

For each of the three traction forces, we compared muscle thicknesses before and during traction using the t-test. We also compared the muscle thickness ratios of the three traction forces using one-way analysis of variance. We used SPSS Statics22, and statistical significance was accepted for values of $\mathrm{p}<5 \%$.

\section{RESULTS}

Table 1 shows the muscle thickness and ratios of each traction load. The ICCs of muscle thickness showed high correlations for both the trapezius muscle (0.968) and the splenius capitis muscle (0.986), indicating that almost the same region was imaged before application of each of the three traction forces.

The trapezius muscle thickness at $5 \mathrm{~kg}$ was $5.89 \pm$ $1.56 \mathrm{~mm}$ before traction, and $5.93 \pm 1.57 \mathrm{~mm}$ during traction, with a muscle thickness ratio of $100.7 \pm 3.62 \%$. Similarly, at $8 \mathrm{~kg}$, the values were $5.98 \pm 1.64 \mathrm{~mm}, 5.94 \pm$ $1.57 \mathrm{~mm}$, and $99.7 \pm 5.85 \%$, respectively. At $11 \mathrm{~kg}$, the values were $6.05 \pm 1.66 \mathrm{~mm}, 5.73 \pm 1.72 \mathrm{~mm}$, and $94.4 \pm 9.04 \%$, respectively. A significant difference in muscle thickness was observed only at $11 \mathrm{~kg}$ between before and during traction. Significant differences in the muscle thickness ratios were found between $11 \mathrm{~kg}$ and 5 and $8 \mathrm{~kg}$.

The splenius capitis muscle thickness at $5 \mathrm{~kg}$ was 8.97 $\pm 1.85 \mathrm{~mm}$ before traction, and $9.07 \pm 1.78 \mathrm{~mm}$ during traction, with a muscle thickness ratio of $101.2 \pm 4.20 \%$. Similarly, at $8 \mathrm{~kg}$, the values were $8.91 \pm 1.88 \mathrm{~mm}, 8.65$ $\pm 1.87 \mathrm{~mm}$, and $97.1 \pm 4.75 \%$, respectively. At $11 \mathrm{~kg}$, the values were $9.02 \pm 1.84 \mathrm{~mm}, 8.32 \pm 1.94 \mathrm{~mm}$, and $91.8 \pm$ $5.32 \%$, respectively. Significant differences in muscle thickness were found at $8 \mathrm{~kg}$ and $11 \mathrm{~kg}$ between before and during traction. Significant differences in muscle thickness ratios were found between $5 \mathrm{~kg}$ and 8 and $11 \mathrm{~kg}$, as well as between $8 \mathrm{~kg}$ and $11 \mathrm{~kg}$.
Table 1. Muscle thickness and muscle thickness ratio of the three traction forces

\begin{tabular}{llcc}
\hline & & Trapezius & Splenius capitis \\
\hline \multirow{2}{*}{$5 \mathrm{~kg}$} & before $(\mathrm{mm})$ & $5.98 \pm 1.56$ & $8.97 \pm 1.85$ \\
& during $(\mathrm{mm})$ & $5.93 \pm 1.57$ & $9.07 \pm 1.78$ \\
& ratio(\%) & $100.7 \pm 3.62$ & $101.2 \pm 4.2$ \\
$8 \mathrm{~kg}$ & before & $5.98 \pm 1.64$ & $8.91 \pm 1.88$ \\
& during & $5.94 \pm 1.57$ & $8.65 \pm 1.87^{*}$ \\
& ratio & $99.7 \pm 5.85$ & $97.1 \pm 4.75^{\dagger}$ \\
$11 \mathrm{~kg}$ & before & $6.05 \pm 1.66$ & $9.02 \pm 1.84$ \\
& during & $5.73 \pm 1.72^{*}$ & $8.32 \pm 1.94^{*}$ \\
& ratio & $94.4 \pm 9.04^{\dagger *}$ & $91.8 \pm 5.32^{\dagger *}$ \\
\hline
\end{tabular}

* indicates a significant difference between before and during, $\mathrm{p}<0.05$

$\dagger$ indicates a significant difference from $5 \mathrm{~kg}, \mathrm{p}<0.05$

indicates a significant difference from $8 \mathrm{~kg}, \mathrm{p}<0.05$

\section{DISCUSSION}

We previously investigated the effects of intermittent cervical traction by analyzing cutaneous blood flow, skin temperature, GSR (galvanic skin response), deep tissue blood flow, and electromyogram frequencies; however, individual differences and the resulting unclear trends made it difficult to obtain a usable index for traction therapy effects $^{1,2)}$. Nonetheless, we believe that basic data of healthy subjects are required to support a more effective traction therapy. Therefore, we investigated the changes that occur in neck muscle thicknesses during traction using an ultrasonic diagnostic device that is commonly used to diagnose and assess motor dysfunction.

In studies measuring muscle thickness using ultrasound ${ }^{3,4)}$, muscle contraction has been shown to increase muscle thickness. Furthermore, the effects of muscle extension are often calculated as changes in muscle/tendon transfer or muscle bundle length ${ }^{5-7)}$. However, muscle thickness has not been used to investigate the effect of cervical vertebra traction.

In this study, we found that the trapezius muscle thickness hardly changed between before and during traction at $5 \mathrm{~kg}$. Muscle extension may not have occurred at this traction force since it is load similar to that exerted by the head, which accounts for roughly $7 \%$ of total body weight. The muscle thickness also remained the same at the $8 \mathrm{~kg}$ load. Considering the physiology of the trapezius muscle, it may not be directly involved in extension during traction, and the effects may be difficult to observe. However, muscle thickness changes were observed at $11 \mathrm{~kg}$, and at $11 \mathrm{~kg}$ significant differences were found from the muscle thickness ratios of $5 \mathrm{~kg}$ and $8 \mathrm{~kg}$. Therefore, extension of the trapezius may require greater traction force.

The splenius capitis muscle thickness did not change at $5 \mathrm{~kg}$, but significant differences were found at $8 \mathrm{~kg}$ and $11 \mathrm{~kg}$. As noted above, a $5 \mathrm{~kg}$ load is similar to the load of the head, and may not induce muscle extension. Physiologically, the splenius muscle can be extended directly through traction, which would explain the significant difference in 
the muscle thicknesses at $8 \mathrm{~kg}$, and the significant difference in muscle thickness ratio at the $8 \mathrm{~kg}$ load from that of $5 \mathrm{~kg}$. The muscle thickness ratio at the $11 \mathrm{~kg}$ load was also significantly different from that of $8 \mathrm{~kg}$, which demonstrates that the stronger traction was effective.

Cervical traction force often begins at $5 \mathrm{~kg}$ and is gradually increased depending on the symptoms. Although this load does not result in muscle extension, it is thought to be appropriate for relieving excessive muscle tension and spasms since at this load, the cervical muscles no longer support the head. Differences in muscle direction between the trapezius and splenius capitis muscles may account for the contrasting results obtained at the $8 \mathrm{~kg}$ traction force. This finding suggests that cervical traction must be performed considering the effects on different neck regions. On the other hand, the $11 \mathrm{~kg}$ traction force was sufficient to affect both muscle groups. However, care is necessary since higher traction forces can lead to stress on the teeth or jaw joints and prevent cervical muscle contractions, causing the traction to become uncomfortable.

The therapeutic objectives of cervical traction are as follows: disarticulation, reduction of extruded disks, extension of soft tissue, muscle relaxation, and joint mobilization. Although studies of the effects of therapy have been performed, some reports have concluded that improvement effects have not been established ${ }^{8}$. Furthermore, other reports have noted the low quality of research involving randomized controlled trials in this field ${ }^{9}$. Thus, the lack of an established traction method and uniform assessment method has led to contrasting evaluations of traction therapy effects. Accordingly, an objective index for evaluating the effectiveness of therapy is necessary to improve this situation. The accuracy and reproducibility of measuring muscle thickness using an ultrasonic diagnostic device has previously been confirmed. However, it is necessary to measure the same region, and some innovations are required for the measurement. In this study, we used a headrest to limit the movement of the neck, an adjustable frame and probe holder to stabilize the probe, and a constant load spring to standardize the contact force. As a result, we obtained high interclass correlation coefficients for muscle thickness before each traction application. We will continue to search for an objective method of assessment to determine the appropriateness of traction therapy as well as changes to the therapeutic parameters. In particular, our research will focus on the non-invasive ultrasonic diagnostic device to broaden the use of this device as an assessment tool in physiotherapy.

\section{REFERENCES}

1) Kuniyasu $K$, Nishimoto $C$, Nishimoto $T$ : Effect of intermittent cervica traction on skin surface blood flow and temperature. Kawasaki Med Welf J, 2001, 11: 149-153.

2) Kuniyasu K, Koga $T$ : Effect of intermittent cervical traction on tissue blood volume and surface electromyography in neck region. Kawasaki Med Welf J, 2007, 17: 129-133.

3) Nakamura S, Katsuhira J, Horimoto Y: Study on the thickness of supraspinatus muscle according to shoulder joint angle change - comparison of no load and load-. Rigakuryoho Kagaku, 2013, 28: 339-342. [CrossRef]

4) Kim HI, Kim SY, Kim TY: Comparison of changes in abdominal muscle thickness using ultrasound imaging during the abdominal drawing-in maneuver performed by patients with low back pain and healthy subjects. J Phys Ther Sci, 2012, 24: 383-385. [CrossRef]

5) Morse CI, Degens H, Seynnes OR, et al.: The acute effect of stretching on the passive stiffness of the human gastrocnemius muscle tendon unit. J Physiol, 2008, 586: 97-106. [Medline] [CrossRef]

6) Mizuno T, Matsumoto M, Umemura Y: Viscoelasticity of the muscletendon unit is returned more rapidly than range of motion after stretching. Scand J Med Sci Sports, 2013, 23: 23-30. [Medline] [CrossRef]

7) Nakamura M, Ikezoe T, Takeno $Y$, et al.: Acute and prolonged effect of static stretching on the passive stiffness of the human gastrocnemius muscle tendon unit in vivo. J Orthop Res, 2011, 29: 1759-1763. [Medline] [CrossRef]

8) Jette DU, Falkel JE, Trombly C: Effect of intermittent, supine cervical traction on the myoelectric activity of the upper trapezius muscle in subjects with neck pain. Phys Ther, 1985, 65: 1173-1176. [Medline]

9) van der Heijden GJ, Beurskens AJ, Koes BW, et al.: The efficacy of traction for back and neck pain: a systematic, blinded review of randomized clinical trial methods. Phys Ther, 1995, 75: 93-104. [Medline] 